Research Article

\title{
Pressure Control of High-Pressure Oil Pipe
}

\author{
Wenrui Qu $\mathbb{D}^{1}{ }^{1}$ Lei Liu $\left(\mathbb{D},{ }^{1}\right.$ and Qun Zhao $\mathbb{D}^{2}$ \\ ${ }^{1}$ School of Mathematics and Statistics, Qilu University of Technology (Shandong Academy of Sciences), University Road 3501, \\ Changqing District, Jinan, Shandong Province, China \\ ${ }^{2}$ Department of Transportation Studies, Texas Southern University, 3100 Cleburne Street, Houston, Texas 77004, USA
}

Correspondence should be addressed to Qun Zhao; qun.zhao@tsu.edu

Received 23 April 2020; Accepted 30 May 2020; Published 29 June 2020

Guest Editor: Ping Zhao

Copyright (C) 2020 Wenrui Qu et al. This is an open access article distributed under the Creative Commons Attribution License, which permits unrestricted use, distribution, and reproduction in any medium, provided the original work is properly cited.

In this paper, to realize the pressure stability control of high-pressure oil pipe, the dynamic differential equation of fuel oil inlet and outlet is established based on the theory of mass conservation. According to the change of the pressure in the high-pressure tubing, an optimization model is established to achieve precise control of the working time of each part of the high-pressure oil pipe.

\section{Introduction}

Fuel entering and ejecting high-pressure fuel pipe is the basis of many fuel engines. When the high-pressure fuel system is working, fuel enters the high-pressure fuel pipe from the oil inlet valve and then ejects from the fuel injector at the other end. The intermittent working process of fuel entering and ejecting will lead to the change of the pressure in the highpressure oil pipe, which will cause the deviation of the quantity of fuel ejected, thus affect the working efficiency of the engine, and even cause the direct economic loss due to the fault $[1,2]$; therefore, it is of great significance to reasonably control the pressure of the high-pressure oil pipe so as to stabilize the pressure in the pipe.

In this paper, a dynamic differential equation of fuel oil inlet and outlet is established based on the theory of mass conservation and a Matlab visual simulation tool is developed. To be more specific, three questions are answered: (1) How to determine the oil supply time of the oneway oil inlet valve? (2) How to determine cam angular velocity? (3) How to adjust the oil supply strategy if adding another injection nozzle?

The following example is used to illustrate the model development and problem-solving process. Figure 1 is the structure of a high-pressure oil pipe. As shown in the picture, the length of the inner cavity of the high-pressure oil pipe is $500 \mathrm{~mm}$, the inner diameter is $10 \mathrm{~mm}$, and the diameter of the small hole A at the oil supply inlet is $1.4 \mathrm{~mm}$.

The oil supply time is controlled by the one-way valve switch, which closes for $10 \mathrm{~ms}$ after each opening. The injector works 10 times per second, and the injection time is $2.4 \mathrm{~ms}$ each time. When the injector is working, the injection rate from nozzle B to the outside is shown in Figure 2. The pressure provided by the high-pressure oil pump at inlet $\mathrm{A}$ is $160 \mathrm{MPa}$, and the initial pressure in the high-pressure oil pipe is $100 \mathrm{MPa}$.

\section{Literature Review}

To solve the pressure control problem of high-pressure oil pipe, He et al. [3] used differential equations and improved continuous differential equation theory to develop a cam angular velocity determination model, a one-way valve control model based on piecewise function fitting and continuous differential equations. In their study, the pressure change in the pipe during the working process of the system was ignored. Lu et al. [4] established a difference equation model to replace the differential equation description, avoided the derivative function in the equation, and solved it in an iterative method, but the accuracy of their model was not as high as that of the differential equation model. Zhang et al. [5] conducted a detailed analysis and 


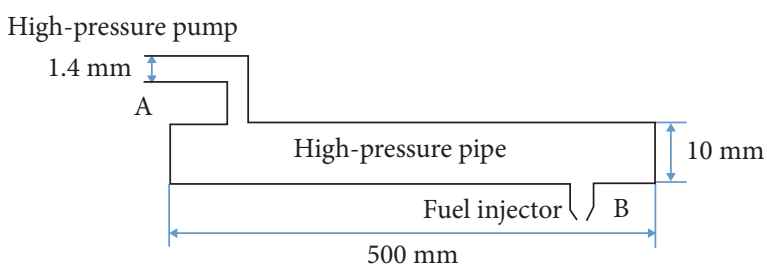

FIgURE 1: Schematic diagram of the high-pressure oil pipe.

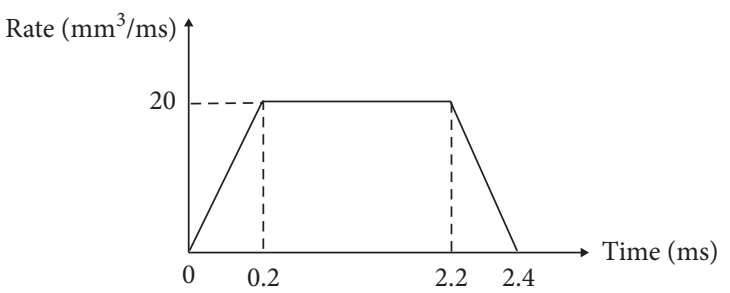

FIgURE 2: Schematic diagram of injection rate.

discussion on how to improve the working efficiency of the system by establishing the simulation mathematical model. However, they did not consider the dynamic process of quality change in the injection process. Wang et al. [6] established the optimization model and solution method of cam speed. However, in their results, the pressure in the tube fluctuated greatly. Zhu [7] used the iterative method to solve the problem. The method is universal, which can not only solve the stable state, but also solve the pressure rise in the high-pressure oil pipe. However, it requires to be able to calculate the state data of each end point of the system, and the iterative algorithm is sometimes not conducive to the solution of the computer. Cai et al. [8] analyzed the control scheme of oil injection strategy from a macro perspective, combined with the data results of two different high-pressure tubing models. The proposed pressure control scheme of highpressure tubing can meet the requirements of different parameters and performance of different high-pressure tubing and can make the pressure in the high-pressure tubing stable, but considering many factors, it is cumbersome.

In this paper, an algorithm based on the differential equation, optimization model, and simulation model was developed. This algorithm can minimize pressure fluctuations and make the solution more accurate.

\section{Symbols and Assumptions}

In order to facilitate the study of the problem and simplify the process of solution, some symbols are uniformly defined and assumptions are made which are consistent with the actual situation.

3.1. Symbols. The symbols and their explanation are provided in Table 1.

\subsection{Assumptions}

(1) The pressure in the high-pressure oil pipe is uniform, regardless of the viscous resistance of the oil
(2) The influence of the change of fuel temperature on the model during the operation of the high-pressure oil pipe is not considered

(3) There will be no fuel leakage in the whole working system

(4) The one-way valve and oil nozzle both work properly

(5) The working condition of the oil nozzle has nothing to do with its position

(6) The opening and closing of the valve are completed instantaneously

\section{Model 1: Dynamic Differential Equation Model}

4.1. Problem 1: How to Determine the Oil Supply Time of the One-Way Oil Inlet Valve? The pressure of oil pipe in unit time is determined by the quantity of oil in $Q_{A}$ and the quantity of oil out $Q_{B}$. According to the given conditions, the functions of the quantity of oil in and out at time $t$, the density $\rho$ of oil, and the internal pressure $P_{2}$ are obtained. Based on the given relationship between the injection rate and time at the fuel injector $B$, the quantity of oil injected $Q_{B}$ can be calculated. Finally, the dynamic pressure equation in the high-pressure oil pipe is established and solved according to the quantity of oil in and out. In this paper, the work of high-pressure oil pipe is divided into adjustment state and stable state. In the adjustment state, the internal air pressure reaches $150 \mathrm{MPa}$ by adjusting the opening time of the one-way valve, and then it enters the stable state; i.e., the amount of oil flowing in and out within a working cycle satisfies the dynamic equation of the high-pressure oil pipe.

4.2. Model Preparation. According to the speed of the oil supply end and the oil outlet end about time $t$, the differential dynamic equilibrium equation is established to solve problem 1.

To unify the dimension in the calculation and derivation process, the following conversion formulas are used to convert the unit:

Unit conversion: $1 \mathrm{~s}=1 \times 10^{3} \mathrm{~ms}, 1 \mathrm{~m}=1 \times 10^{3} \mathrm{~mm}$, $1 \mathrm{MPa}=1 \times 10^{6} \mathrm{~Pa}$

Circle area formula: $s=\pi r^{2}=\pi(d / 2)^{2}$

Column volume formula: $V=\pi r^{2} h$

4.3. Model Establishment. When the pressure in the pipe is stable at $100 \mathrm{MPa}$, the dynamic differential equation model was developed following the three steps:

Step 1. Calculate the quantity of oil $Q_{A}$ flowing into oil supply end A.

According to the flow formula, the oil supply quantity is calculated:

$$
Q_{A}=C A \sqrt{\frac{2 \Delta P}{\rho}}=C A \sqrt{\frac{2}{\rho}(P 1-P 2)},
$$


TABLE 1: Symbols and explanation.

\begin{tabular}{lcc}
\hline Symbol & Explanation & Unit \\
\hline$Q_{\text {A }}$ & The oil supply quantity at the oil supply end A in t time & $\mathrm{m}^{3} / \mathrm{s}$ \\
$Q_{\text {B }}$ & Output of fuel injection end in one injection time & $\mathrm{m}^{3} / \mathrm{s}$ \\
$\rho$ & Density of fuel & $\mathrm{m}^{2}$ \\
$A$ & The area of the small circular hole area & $\mathrm{Pa}$ \\
$E$ & Modulus of elasticity & $\mathrm{Pa}$ \\
$P_{1}$ & Supply end pressure & $\mathrm{Pa}$ \\
$P_{2}$ & Total volume of high-pressure oil pipe & $\mathrm{m}$ \\
$P(t)$ & Pressure variation function in tube & $\mathrm{s}$ \\
$V$ & Internal pressure of high-pressure oil pipe & \\
$T$ & One working cycle of high-pressure oil pump & \\
\hline
\end{tabular}

where flow coefficient $C=0.85$ and the area of the hole $A=\pi r^{2}=\pi(d / 2)^{2}=3.14 \times\left(\left(1.4 \times 10^{-3}\right) / 2\right)^{2}=$ $1.5386 \times 10^{-6} \mathrm{~m}^{2}$

According to the data that indicates the relationship between the elastic modulus $E$ and pressure, by using the polyfit function in Matlab to fit a 3th-degree polynomial, the function of elastic modulus on pressure can be obtained:

$$
E(P)=a P^{3}+b P^{2}+c P+d .
$$

Then, based on the fact that the pressure change of fuel is proportional to the density change and the ratio coefficient is $E / \rho$, the function between density and the change of pressure can be derived; that is,

$$
\Delta P=\frac{E}{\rho} \Delta \rho \mathrm{m}^{3} / \mathrm{s} .
$$

The simplified expression is

$$
\Delta P=\int_{P_{1}}^{P} \frac{\mathrm{d} P}{E}=\ln \frac{\rho_{1}}{\rho_{0}} \mathrm{~m}^{3} / \mathrm{s} .
$$

To sum up, within the time period $T$, the quantity of oil supply can be expressed as

$$
Q_{\mathrm{A}}= \begin{cases}C A \sqrt{\frac{2}{\rho}\left(P_{1}-P_{2}\right)}, & 0 \leq t<T \\ 0, & T \leq t \leq T+0.01\end{cases}
$$

Step 2. Calculate the oil output $Q_{B}$ at the oil injection end $B$.

According to the graph of oil injection rate and time, as shown in Figure 2, the resolution function corresponding to each segment is calculated separately to obtain the flow velocity function at the injection end:

$$
V_{B}= \begin{cases}q_{1}=0.1 t, & 0 \leq t<0.0002, \\ q_{2}=2 \times 10^{-5}, & 0.0002 \leq t<0.0022, \\ q_{3}=2 \times 10^{-5}-1 \times 10^{-4}(t-2.2), & 0.0022 \leq t<0.0024, \\ 0, & 0.0024 \leq t<0.1 .\end{cases}
$$

According to the integration of time $t$, the outflow volume in one injection process is

$$
Q_{B}=\int\left(q_{1}+q_{2}+q_{3}\right) \mathrm{d} t
$$

Step 3. Establish the dynamic pressure equation in the high-pressure oil pipe.

Based on the quantity of oil in and out, the dynamic pressure equation in the high-pressure oil pipe can be expressed as

$$
P=\int \frac{E}{V}\left(Q_{A}-Q_{B}\right)
$$

where $V=\pi r^{2} h=3.14 \times\left(\left(1 \times 10^{-2}\right) / 2\right)^{2} \times 0.5=3.925 \times$ $10^{-5} \mathrm{~m}^{3}$.

By fitting the search function, the change of $P$ is ensured to be as small as possible so that the pressure in the highpressure tubing is maintained at about $100 \mathrm{MPa}$.

When the pressure in the pipe increases to $150 \mathrm{MPa}$, the working state of high-pressure oil pipe can be divided into adjustment state and stable state. In the adjustment state, the opening time of one-way valve is adjusted by time $T_{1}(2 \mathrm{~s}, 5 \mathrm{~s}, 10 \mathrm{~s})$; after $T_{1}$ period, the pressure in the oil pipe reaches $150 \mathrm{MPa}$. Set the opening time of the valve at the oil supply end as $T_{0}$; we can get $Q_{A 1} \cdot T_{0}+Q_{0}=Q_{1}-Q_{B} \cdot T_{1}$.

Then, formula (5) is improved to

$$
Q_{A 1}= \begin{cases}C A \sqrt{\frac{2}{\rho}\left(P_{1}-P_{2}\right)}, & 0 \leq t<T_{0}, \\ 0, & T_{0} \leq t \leq T_{1} .\end{cases}
$$


Finally, the high-pressure oil pipe enters the next working state. In the stable state, the working principle of the tubing is similar to the previous analysis. Based on the quantity of oil in and out, the dynamic pressure equation in the high-pressure pipe is established as follows:

$$
\begin{aligned}
P & =\int \frac{E}{V}\left(Q_{A 2}-Q_{B}\right), \\
Q_{A 2} & = \begin{cases}C A \sqrt{\frac{2}{\rho}\left(P_{1}-P_{2}\right)}, & T_{1} \leq t<T, \\
0, & T \leq t \leq T+0.01 .\end{cases}
\end{aligned}
$$

By fitting the search function, the change is kept as small as possible so that the pressure in the high-pressure tubing is maintained at about $150 \mathrm{MPa}$ :

$$
\begin{aligned}
T & =2 \mathrm{~s}: P(t)=100+0.025 t, \\
\rho(t) & =0.85+4.34 \times 10^{-4} t, \\
T & =5 \mathrm{~s}: P(t)=100+0.01 t, \\
\rho(t) & =0.85+1.74 \times 10^{-4} t, \\
T & =10 \mathrm{~s}: P(t)=100+0.005 t, \\
\rho(t) & =0.85+8.68 \times 10^{-5} t .
\end{aligned}
$$

The equation is established by converting the pressure difference into the mass difference:

$$
\Delta m=m_{A}-m_{B}
$$

where

$$
m_{A}=\rho \int_{0}^{T} C A \sqrt{\frac{2(160-P(t))}{\rho_{160}}} \mathrm{~d} t .
$$

It can be seen that the opening time of the oil pipe is reduced when the pressure in the pipe increases from $100 \mathrm{MPa}$ to $150 \mathrm{MPa}$.

\subsection{Problem Solving}

Step 1. The elastic modulus $E$ is fitted by the third-order function (2) of the polyfit function in Matlab, and the fitting error is analyzed.

The functional relationship between the elastic modulus and the pressure is obtained:

$$
\begin{aligned}
E(P)= & 1.00037752 \times 10^{-4} P^{3}-1.082481397 \times 10^{-3} P^{2} \\
& +5.474444341310 P+1.531868405848778 \times 10^{3} .
\end{aligned}
$$

Figure 3 shows a comparison between the fitting curve and the given data.

It can be seen from the fitting comparison chart that the fitting curve has a high degree of agreement with the original data set, and the cubic fitting effect is good, which can accurately describe the functional relationship between elastic modulus $E$ and pressure $P$.

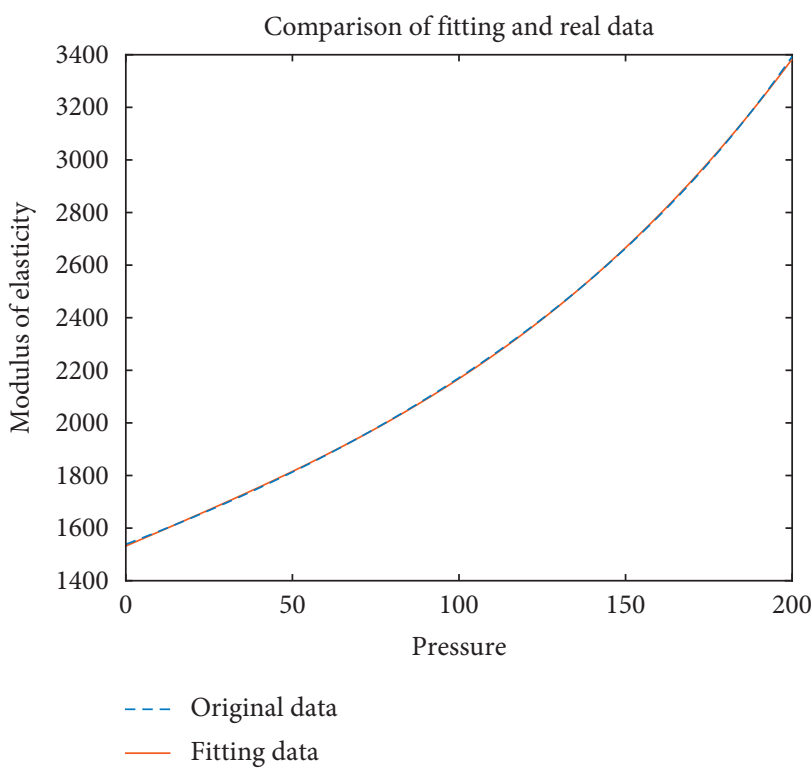

FIgURE 3: Comparison between the fitting curve and original data.

Step 2. Calculation of oil output $Q_{B}$.

The flow rate function integrates the time $t$ to obtain the outflow of the primary injection process $2.4 \times 10^{-3} \mathrm{~s}$ :

$$
\begin{aligned}
Q_{B}= & \int\left(q_{1}+q_{2}+q_{3}\right) \mathrm{d} t, \\
= & \int_{0}^{0.0002} 0.1 t \mathrm{~d} t+\int_{0.0002}^{0.0022} 2 \times 10^{-5} \mathrm{~d} t \\
& +\int_{0.0022}^{0.0024} 2 \times 10^{-5}-1 \times 10^{-4}(t-2.2) \mathrm{d} t, \\
= & 4.4 \times 10^{-8} \mathrm{~m}^{3} / \mathrm{s} .
\end{aligned}
$$

Step 3. Bring in dynamic pressure equation (10), and the following results are obtained:

$$
\begin{aligned}
P & =1 \times 10^{8}=\int \frac{E}{V}\left(Q_{A}-Q_{B}\right) \mathrm{d} t \\
& =\int \frac{E\left(1 \times 10^{8}\right)}{3.925 \times 10^{-5}}\left(Q_{A}-4.4 \times 10^{-8}\right) \mathrm{d} t .
\end{aligned}
$$

With Matlab, it could be found that $T=3.06 \mathrm{~ms}$, which means when the opening time of one-way valve is $3.06 \mathrm{~ms}$, the pressure in the high-pressure oil pipe could be stable at $100 \mathrm{MPa}$.

Step 4. When the pressure in the high-pressure oil pipe is stable at $150 \mathrm{MPa}$, if working process of the high-pressure oil pump is divided into the adjustment stage and the balance stage, then the working rules of the oil pump under the three adjustment stages are as follows:

$$
\begin{aligned}
& \text { The } \begin{array}{ll}
\text { adjustment } & \text { process }
\end{array} \text { is as follows: } \\
& T_{2}= \begin{cases}0.898 \mathrm{~ms} / \text { time } & t \in[0,2] \\
0.761 \mathrm{~ms} / \text { time } & t \in(2, \infty)\end{cases}
\end{aligned}
$$




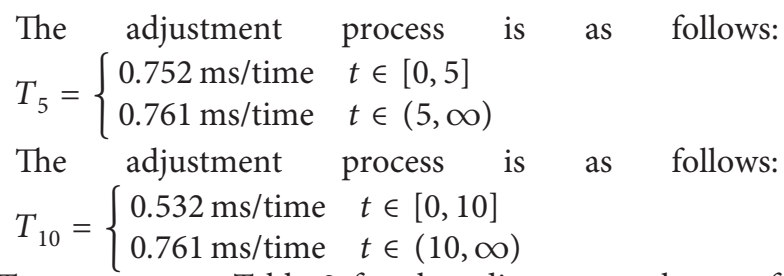

To sum up, see Table 2 for the adjustment scheme of three times. It can be seen that when the adjustment process is $2 \mathrm{~s}$, the opening time of high-pressure oil pump is $0.898 \mathrm{~ms}$ each time within $0-2 \mathrm{~s}$, and when it reaches a stable state after $2 \mathrm{~s}$, the single opening time of oil pump is $0.761 \mathrm{~ms}$.

\section{Model 2: Dynamic Pressure Model of Liquid Mass}

5.1. Problem 2: How to Determine Cam Angular Velocity? When the pressure and other factors change, the constant is the quality of the liquid in the fuel supply end and the quality of the liquid out of the fuel injection end. In a working cycle of the high-pressure oil pipe system, in order to maintain the stability of the pressure in the pipe, the quality of the fuel in and out is equal.

For problem 2, the fuel supply end compresses the lowpressure fuel oil by the rotation of the cam. Firstly, according to the relationship between the cam edge curve and the angle, combined with the working data of the plunger system, the movement range of the plunger is 0 to $10.626 \mathrm{~mm}$. The rotation angle of the plunger from the compression to the low point, after the compression to the high point, then back to the low point is $\theta$, and the amount of oil pressed is $Q_{A}$. This process is recorded as one working cycle T. Next, according to the movement curve of the needle valve and the geometry of the injector nozzle [9], the relation curve between the injection rate and the time is obtained, and the mass of the fuel injected in unit time $m_{B}$ is calculated. Then a working cycle $T=\left(m_{A}^{\prime} / m_{B}\right) \times 1 \mathrm{~s}$ at the oil supply end is calculated, and finally, the cam angular velocity $\omega=\theta / T$ is obtained.

5.2. Model Preparation. In the whole working system of high-pressure oil pipe, the pressure in the pipe can be kept stable only when the mass of injected fuel is always equal. The following gives the concept of conservation of mass and its application formula.

Conservation of mass: in any isolated system, the total mass remains unchanged no matter what changes or processes occur. In other words, any changes, including chemical reaction and nuclear reaction, can not eliminate substances but changes the original form or structure of substances, so this law is also known as the law of material immortality [10].

Liquid mass, density, volume relationship: $m=\rho v$.

\subsection{Problem Solving}

Step 1. Calculate the mass $m_{A}^{\prime}$ of the injection flow $Q_{A}$ in a working cycle $T$; the schematic diagram of the high-pressure oil pump is as shown in Figure 4.
TABLE 2: Adjustment plan.

\begin{tabular}{lccc}
\hline Status time & $2 \mathrm{~s}$ & $5 \mathrm{~s}$ & $10 \mathrm{~s}$ \\
\hline Adjustment status (ms/time) & 0.898 & 0.752 & 0.532 \\
Stable status (ms/time) & 0.761 & 0.761 & 0.761 \\
\hline
\end{tabular}

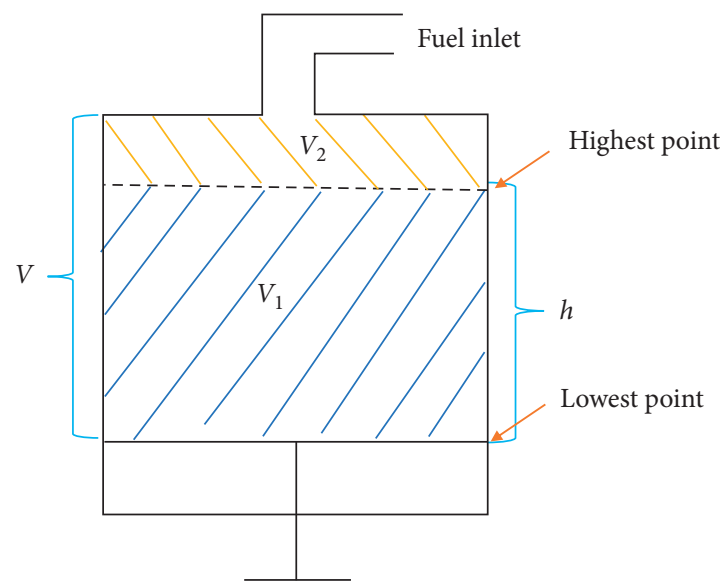

FIgURE 4: Schematic diagram of the high-pressure oil pump.

Fit the relationship between the cam edge curve and the angle, and the result is shown in Figure 5.

The maximum compression value of cam is $h=5.313-$ $(-5.313)=10.626 \mathrm{~mm}$; that is, the compression range is $0 \sim 10.626 \mathrm{~mm}$. The plunger is compressed from the low point to the high point and returns to the original position, which is recorded as a cycle $T$, and the effective volume of ramrod compression is $V_{1}=s h=\pi \times \quad\left(\left(5 \times 10^{-3}\right) / 2\right)^{2} \times$ $1.0826 \times 10^{-2} \mathrm{~m}^{3}$. The residual volume of the plunger rod is $V_{2}=2 \times 10^{-8} \mathrm{~m}^{3}$, so the total volume of the plunger bar is $V=\left(V_{1}+V_{2}\right) m^{3}$.

When the plunger is at a low point, the fuel pressure is $0.5 \mathrm{MPa}$; according to the density formula $\Delta P=(E / \rho)$ $\Delta \rho \mathrm{m}^{3} / \mathrm{s}$, the density is calculated as $\rho_{0}$. When the plunger is at the highest point, because the pressure in the plunger cavity is greater than the pressure in the high-pressure oil pipe, the check valve connecting the plunger cavity and the high-pressure oil pipe is opened, so the pressure in the pipe can be regarded as $100 \mathrm{MPa}$. According to the density formula, the corresponding fuel density is $\rho_{1}$. The quality of fuel that is pressed into the high-pressure fuel line in one cycle is $m_{A}^{\prime}=\rho_{0} V-\rho_{1} V_{2}$.

Step 2. Calculate the mass $m_{B}$ of the ejected flow $Q_{B}$ in one second.

The schematic diagram of the injector nozzle is shown in Figure 6.

In the initial stage, that is, when the needle valve is closed, the height $h_{1}$ from the bottom to the top of the cone meets the following requirements: $\left(\left((2.5 / 2) \times 10^{-3}\right) / h_{1}\right)=$ $\tan 9^{\circ}$, reduced to $h_{1}=\left(\left(1.25 \times 10^{-3}\right) / \tan 9^{\circ}\right)=7.892 \times$ $10^{-3} \mathrm{~m}$. In the process of needle valve rising, the flow rate of fuel increases gradually. When the lower end of the needle valve reaches the height $h_{2}$, that is to say, the area of the circular ring formed by the bottom of the needle valve and 


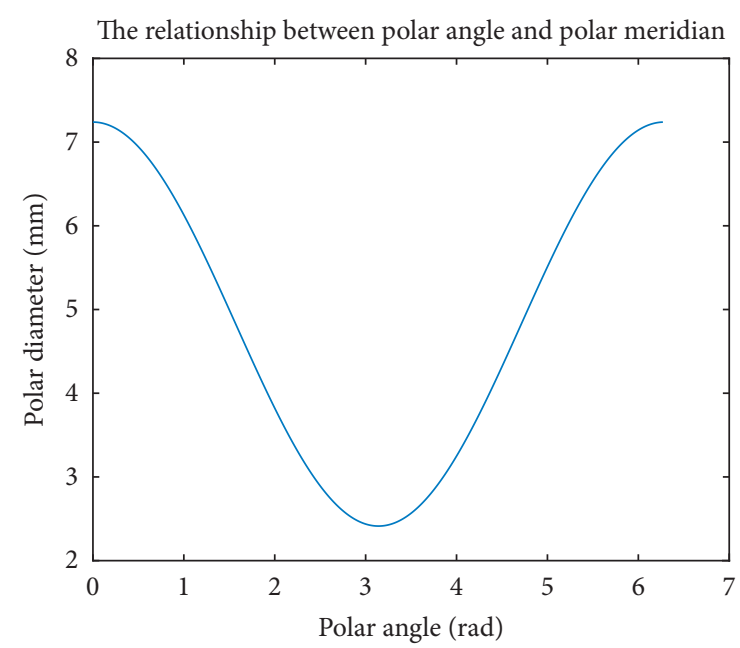

FIGURE 5: Fitting curve of polar diameter and polar angle.

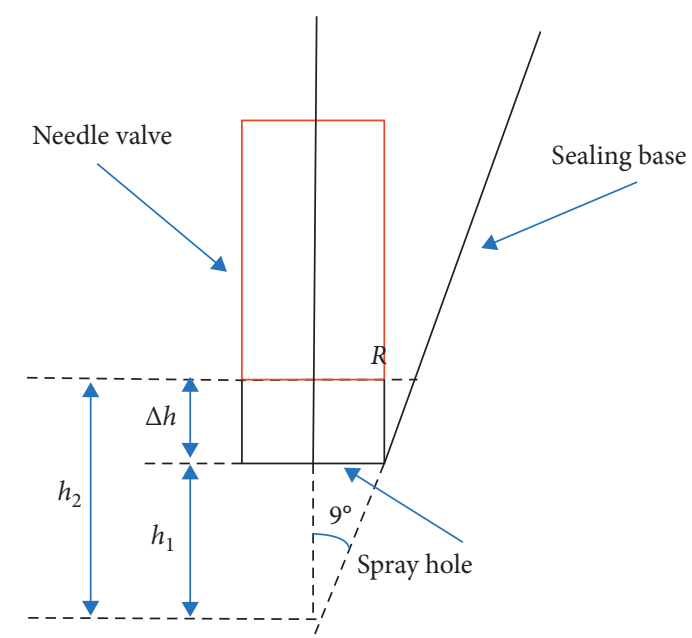

FIgURE 6: Structure of the fuel injection nozzle.

the inner surface of cone $S$ is equal to the area of a small hole, the flow rate reaches the maximum. At this time, the outer radius $R$ of a circular ring meets the requirements: $\pi R^{2}-\pi\left(1.25 \times 10^{-3}\right)^{2}=\pi\left(0.7 \times 10^{-3}\right)^{2}$. The result is $R=1.433 \times 10^{-3} \mathrm{~m}$. In a right triangle, $h_{2}=\left(R / \tan 9^{\circ}\right)=$ $9.045 \times 10^{-3} \mathrm{~m}$, and the rising height of the needle valve is as follows:

$$
\Delta h=h_{2}-h_{1} \begin{cases}=0, & \text { the flow rate is } 0, \\ \in(0,1.153], & \text { flow rate increases, } \\ >1.153, & \text { velocity unchanged } \\ \in[1.153,0), & \text { velocity decreases. }\end{cases}
$$

Performing three times fitting for the given needle method motion, the fitting curve is shown in Figure 7.

According to the rising height node of needle valve, the time node of flow rate change can be obtained, and then the functional relationship between flow rate and ring area can be obtained:

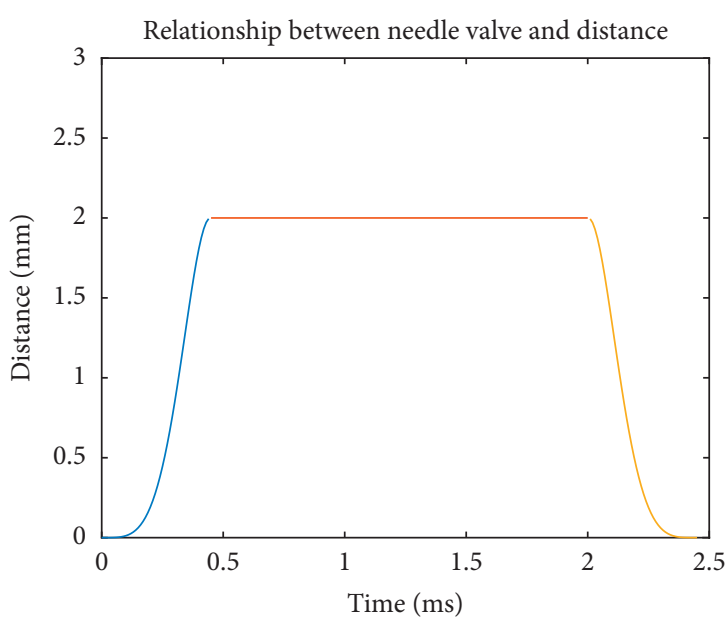

Figure 7: Curve of moving distance and time of needle valve.

$$
Q=C S \sqrt{\frac{2 \Delta P}{\rho}} .
$$

To sum up, the quality of oil ejected in unit time is $m_{B}=Q \times T \times \rho_{100}=0.85 Q$.

Step 3. Balance stage.

To make the pressure in the high-pressure oil pipe at $100 \mathrm{MPa}$, that is, $m_{\mathrm{A}}=m_{\mathrm{B}}$; then,

$$
T=\frac{m_{A}^{\prime}}{m_{A}} \times 1 \mathrm{~s}=\frac{m_{A}^{\prime}}{m_{B}} \times 1 \mathrm{~s} .
$$

The angular velocity of the cam is $\omega=\theta / T$, where $\theta=6.27 \mathrm{rad}$.

The speed curve of the injection end is shown in Figure 8.

The results obtained by taking the known data into formula (20) are as follows:

$$
\begin{aligned}
m_{A}^{\prime} & =151.2711 \mathrm{mg}, \\
m_{B} & =329.493 \mathrm{mg}, \\
T & =\frac{m_{A}^{\prime}}{m_{B}} \times 1 \mathrm{~s}=1.02 \mathrm{~s}, \\
\omega & =\frac{\theta}{T}=27.243 \mathrm{rad} / \mathrm{s} .
\end{aligned}
$$

\section{Model 3: Dynamic Model of Double Nozzles}

6.1. Problem 3: How to Adjust the Oil Supply Strategy If Another Injection Nozzle Is Added? If adding another injection nozzle with the same working rule based on the model developed in Problem 2, without considering the influence of its position distribution. Then installing another pressure relief valve to control the pressure in the high-pressure oil pipe. According to the previous analysis, the pressure relief valve is opened and the fuel returns when the pressure in the high-pressure oil pipe is greater than $100 \mathrm{MPa}$. In the whole 


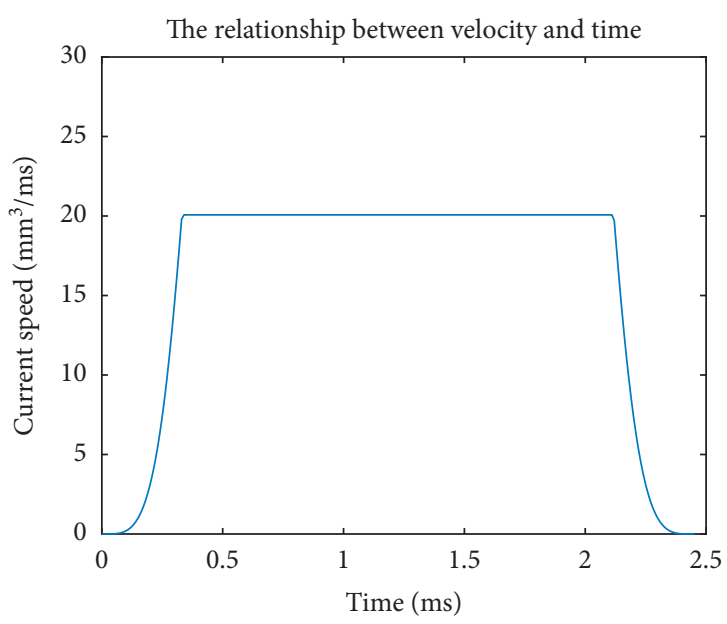

Figure 8: Curve of velocity versus time.

process of pressure regulation, the minimum pressure fluctuation of a system is the optimal objective, and a single objective programming model is established based on the constraint equation of fuel quality [11]. The changed oil pipe is shown in Figure 9.

6.2. Model Preparation. In the calculation of high-pressure oil pump, a function is used to fit the change of oil supply pressure.

Fitting is to connect a series of points on a plane with a smooth curve. Generally, the fitting curve can be expressed by function, and a commonly used fitting method is the least square curve fitting method. In Matlab, polyfit can also be used to fit polynomials.

6.3. Problem Solving. Adding an injector with the same working rule, that is, there are two injectors in the system, which are recorded as $q_{1}$ and $q_{2}$, respectively, regardless of the impact of their location distribution. Two scenarios are considered when solving this problem.

Scenario 1. The starting working time of two fuel injection nozzles is the same.

Adding an injector with the same working rule based on problem 2, in this case, it can be considered that the oil output in the same time is 2 times that in question 2 , and the time to achieve stable oil pressure in the pipe is $1 / 2$ of the original.

In unit time, the quality of the oil out of the injector end is $m_{B}^{\prime}=2 m_{B}$, and the amount of oil in a working cycle $T$ of the injector end $A$ in a cycle remains unchanged to $m_{A}^{\prime}$. With equation (18),

$$
T^{\prime}=\frac{m_{A}^{\prime}}{2 m_{B}} \times 1 \mathrm{~s}=\frac{T}{2} .
$$

And the angular velocity of the cam is

$$
\omega^{\prime}=\frac{\theta}{T^{\prime}}=2 \omega=54.486 \mathrm{rad} / \mathrm{s}
$$

Scenario 2. The starting working time of two fuel injection nozzles is inconsistent.

If nozzle $q_{1}$ starts to work from 0 and nozzle $q_{2}$ starts to work from $t$, then in $t$ time, the oil delivery quality of the system is

$$
m_{2}= \begin{cases}\int_{0}^{T} C A \sqrt{\frac{2\left(P_{1}-P_{2}\right)}{\rho_{1}}} \mathrm{~d} t, & T<t, \\ \int_{0}^{T} C A \sqrt{\frac{2\left(P_{1}-P_{2}\right)}{\rho_{1}}} \mathrm{~d} t+\int_{t}^{T} C A \sqrt{\frac{2\left(P_{1}-P_{2}^{\prime}\right)}{\rho_{1}}} \mathrm{~d} t, & T<t .\end{cases}
$$

In the whole process of pressure regulation, the minimum pressure fluctuation of a system is the optimal objective, and the objective function is $\min \int_{0}^{T}|P(t)|-100 \mathrm{~d} t$.

The constraints are

$$
\text { s.t }\left\{\begin{array}{l}
C A \sqrt{\frac{2\left(P_{1}-P_{2}\right)}{\rho_{1}}}+\frac{\mathrm{d} m}{\mathrm{~d} t}=0, \\
T=\frac{2 \pi t}{\omega} .
\end{array}\right.
$$

A single objective programming model is established, the optimal angular velocity of the cam is $245.63 \mathrm{rad} / \mathrm{s}$ in a system cycle, and the initial working time difference of the two nozzles is $1 / 2$ cycle.

When adding a pressure reducing valve, if taking time as an independent variable, the fuel oil pressure input and nozzle injection could be calculated. By multiplying the difference by the elastic modulus $E$, the derived formula is

$$
P=\int \frac{E}{V}\left(Q_{A}-Q_{B}\right) \mathrm{d} t .
$$

It is simulated circularly and the image is drawn. The simulation results are shown in Figure 10.

It can be seen from Figure 10 that when the single valve is not working, the air pressure in the high-pressure oil pipe will fluctuate up and down, which is not stable. When the single pressure reducing valve is opened, the simulation results are as shown in Figure 11.

After opening, the pressure in the pipe tends to be stable, and the pressure reducing valve plays an important role in stabilizing the air pressure in the tubing when the working time is about $20 \mathrm{~ms}$.

\section{Model Validation}

Inspection idea: during the working process of high-pressure oil pipe, when the pressure inside the oil pipe fluctuates within a certain range, it can be regarded as stable, which can increase the service life of the whole oil supply system. In this paper, the real-time monitoring of the pressure in the tube during the working process of the oil tube is carried out, and the change curve of the pressure in the tube with time $t$ is drawn, as shown in Figure 12. 


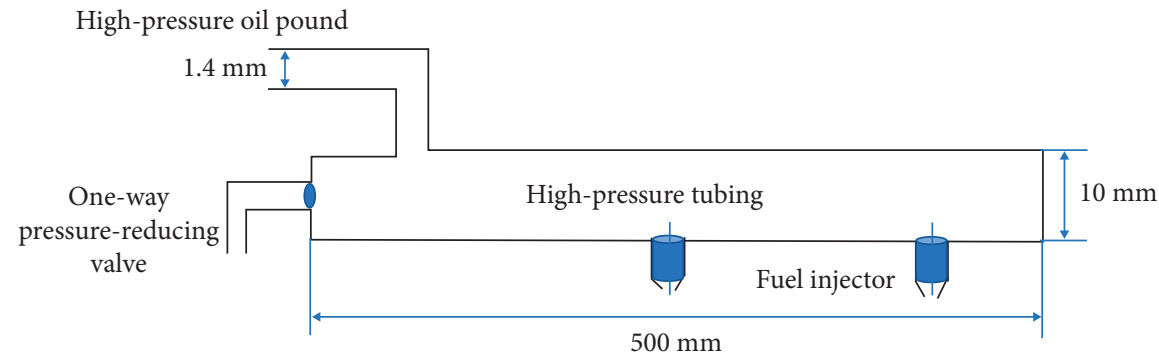

FIgURE 9: Schematic diagram of high-pressure oil pipe.

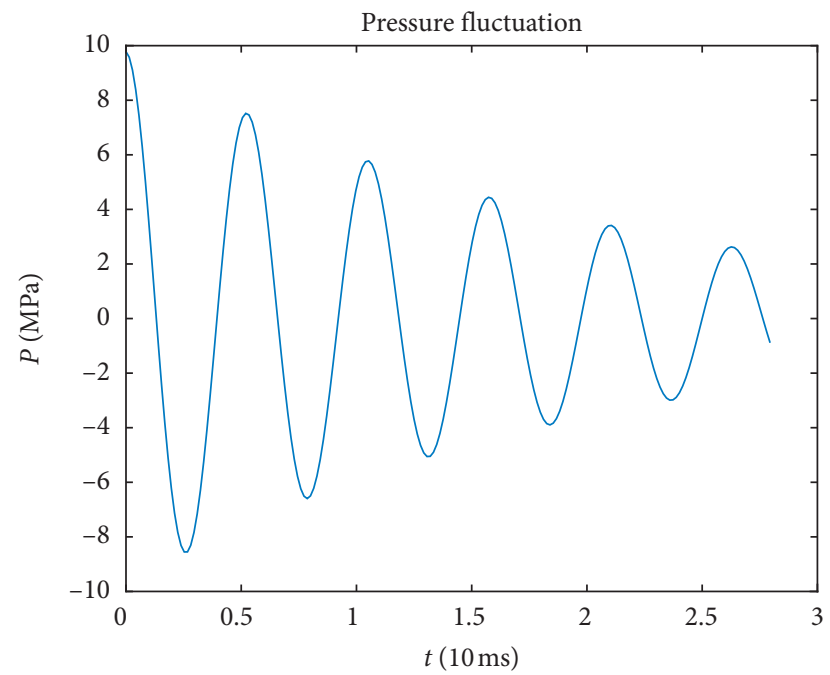

FIGURE 10: Simulation results of internal pressure.

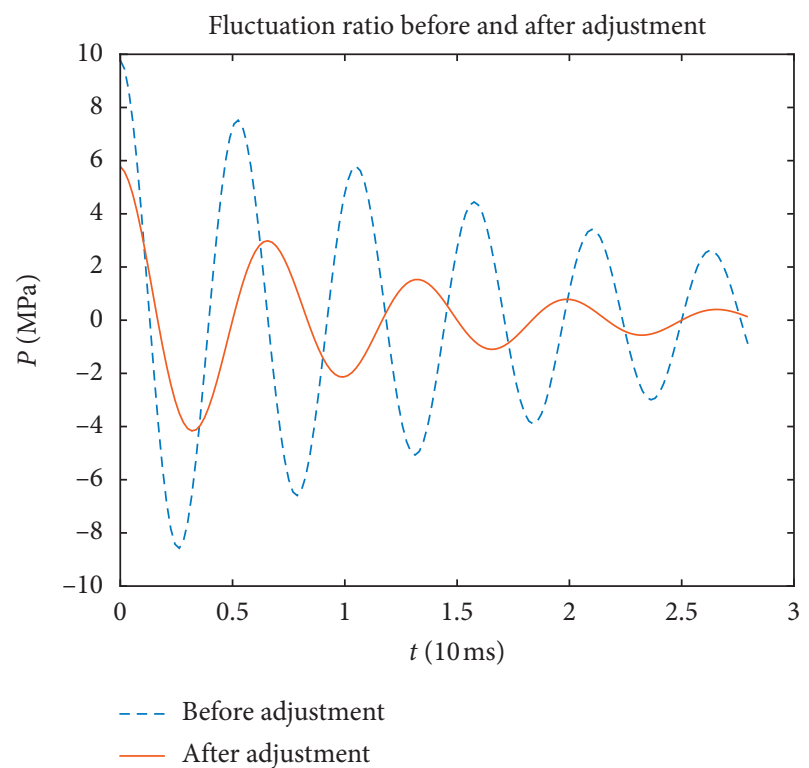

FIgURE 11: Air pressure simulation diagram after adding single pressure reducing valve.

It can be seen that, during the working process of highpressure oil pipe, the air pressure in the pipe always changes periodically between $96 \mathrm{MPa}$ and $104 \mathrm{MPa}$, and the pipe can

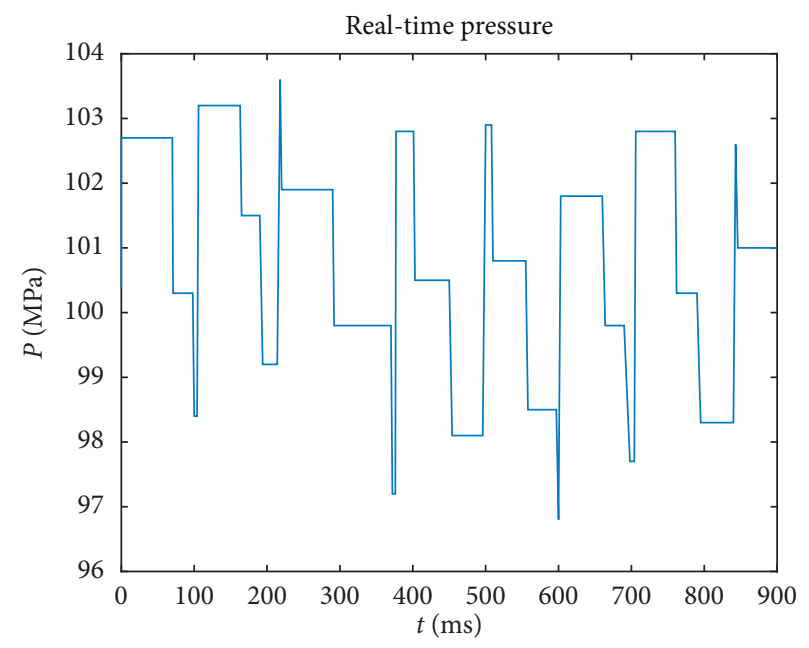

FIGURE 12: Real-time pressure.

be regarded as a stable state, which shows that the model has precise control on all parts of the oil pipe, thus making the whole oil supply system more stable.

\section{Model Evaluation}

\subsection{Advantages}

(1) In the dynamic differential equilibrium equation model of question 1, the time is subdivided, the relation between the oil supply rate and the pressure difference and time is fully considered, and the oil supply end is precisely controlled by the flow rate of the oil injection end; in the adjustment state, the linear function is used to fit the pressure change in the high-pressure oil pipe, which simplifies the solution.

(2) In the process of solving the second problem, based on the conservation of mass, a dynamic equation model with mass as the link is established, and a constant quantitative equation is established in many variable quantities to eliminate the interference of temperature and other factors on the solution process.

(3) In the process of solving problem 3, this paper adopts the method of function fitting to eliminate the influence of the irregular change of oil supply of high- 
pressure oil pump on the solution of the problem and improve the efficiency of the solution.

(4) Finally, for the model testing, the simulation model is established to test the working system of highpressure oil pipes one by one [12]. It is a powerful simulation tool, which enables users to simulate the operation of a real dynamic system with the minimum cost in the graphic mode, and can establish the dynamic system model and carry out simulation model in an intuitive way, and use the visual modeling, which can quickly and accurately build the block diagram model of the dynamic system, and improve the accuracy and reliability of the model.

\subsection{Disadvantages}

(1) In the process of solving problem one, because of the particularity of solving a differential equation, the analytical solution is difficult to solve. In this paper, the numerical solution is used for approximate substitution, resulting in errors.

(2) In this paper, the change of system temperature caused by friction and other factors is not considered in the model.

8.3. Conclusion. To sum up, the purpose of this paper is to study the pressure control problem of the high-pressure oil pipe of the fuel engine, with the known parameters to calculate the pressure density and other indexes by using the numerical solution of differential equation flexibly. The fluid density and pressure model of high-pressure oil pipe are established, and the pressure stability of high-pressure oil pipe is maintained by using visual simulation tools. At the same time, the control scheme of fuel injection nozzle and pressure relief valve is studied to precisely control the working time of each part of high-pressure oil pipe, so as to improve the service life of engine.

\section{Future Work}

In reality, there will be differences in the pressure in the high-pressure oil pipe, which is related to the elastic deformation in the pipe, the transmission mode of fuel in the pipe, and other factors. The function of the pressure in the pipe can be constructed to refine the change of the pressure in the pipe, to quantify the injection rate at the injection end more accurately, as to precisely regulate the oil supply end.

In the solution model of problem 2, the fuel supply end drives the plunger to pressurize the low fuel oil through the cam rotation. In this process, due to the influence of friction, the volume and pressure of fuel oil will be affected. Therefore, the temperature influence factor can be added in the process of solving the fuel supply quality to eliminate the influence of temperature change.

In question 3 , the position of the fuel injector will affect the injection rate [13]. Theoretically, the closer the position of the fuel injector is to the fuel supply end, the greater the injection rate is. The position of the two fuel injectors relative to the fuel supply end can be considered to comprehensively adjust the oil supply time, which is more practical.

In the working system of high-pressure oil pipe, the model in this paper realizes the mutual correlation and precise regulation of various components. In the era of the rapid development of big data, the model can be applied to the sensing process of the robot, self-regulation of medical instruments and correction equipment, etc. [14], which has a wide application prospect and research value.

\section{Data Availability}

The cam edge curve, needle valve motion curve, and elastic modulus pressure data used to support the findings of this study are available from the corresponding author upon request.

\section{Conflicts of Interest}

The authors declare that they have no conflicts of interest.

\section{References}

[1] H. Jiangfeng, W. Xiang, and Y. Changcheng, "Modal analysis of high-pressure oil pipe of engine based on finite element method," Journal of Hubei Institute of Automotive Industry, vol. $4,2018$.

[2] H. Shuangiie, Research on High-Pressure Common Rail Injection System of Diesel Engine, Hangzhou University of Electronic Science and technology, Hangzhou, China, 2018.

[3] Y. He, Z. Jiaming, G. Zhengshuai et al., "Study on pressure control of high-pressure tubing based on continuous differential equation," Journal of Qilu University of Technology, vol. 33, no. 6, pp. 74-80, 2019.

[4] Y. Lu, W. Shen, and X. Qian, "Pressure control of highpressure tubing based on difference equation," Science and Technology Innovation and Application, vol. 7, pp. 25-27, 2020.

[5] A. Zhang, W. Zhao, X. Zhang, Y. Wang, and Z. Su, "Research on pressure control theory of high-pressure tubing based on simulation model," Electronic Testing, vol. 1, pp. 63-65, 2020.

[6] Y. Wang, W. Liu, and S. Yao, "Optimization model and application of high-pressure tubing pressure control," Science and Technology Innovation and Application, vol. 36, pp. 2022, 2019.

[7] D. Zhu, "Iterative teaching in mathematical modeling," Chinese Journal of Multimedia and Network Teaching, vol. 5, pp. 239-241, 2020.

[8] J. Cai, Y. Lin, Li Shu, S. Xu, and J. Zeng, "Modeling and numerical analysis of a class of high-pressure tubing control problems," Contemporary Chemical Research, vol. 9, pp. 3639, 2020.

[9] Y. Wang, Design and Numerical Calculation of Fuel Injection System for Medium and High-Speed Diesel Engines, Harbin Engineering University, Harbin, China, 2004.

[10] Y. Song, Simulation of Pressure Dynamic Characteristics of High-Pressure Common Rail System of Diesel Engine, Zhejiang University, Hangzhou, China, 2005.

[11] H. Xiao, Dictionary of Decision Science, People's Publishing House, Beijing, China, 1995.

[12] S. Liu, T. Dong, R. Meng et al., "Study on simulation design of diesel engine injection process," Journal of Internal Combustion Engine, no. 2, pp. 56-65, 1990. 
[13] P. Linop, B. Maione, and A. Brizzo, "Nonlinear modeling and control of a Common rail injection system for diesel engines," Applied Mathematical Modelling, vol. 31, no. 9, pp. 1770-1784, 2007.

[14] Q. Wang, B. Hu, C. Xiao, and Y. Su, "Development and application of ultra-high-pressure strengthening technology for high-pressure oil pipe of diesel engine," Mechanical Engineer, vol. 5, 2013. 